\title{
Development of health technology assessment in Lithuania
}

\author{
Jankauskiene Danguole \\ Mykolas Romeris University
}

\begin{abstract}
Objectives: To describe how Lithuania is attempting to develop health technology assessment (HTA) structures.

Methods: The case study of the history of development of HTA in Lithuania is presented. Results: Historical steps of HTA development are as follows: in 1993, a few conferences on HTA; eight people were trained in Sweden at SBU; the book First Steps of HTA in Lithuania (5) was issued together with SBU in 1993; participation in the International Society of Technology Assessment in Health Care (ISTAHC) conferences; participation in development of training courses and European networks of HTA; new people in HTA were trained in health accreditation service, Sickness Fund, and Ministry of Health. The major step was establishment of an evidence-based medicine library. In 1994, Article 54 in the Health Care System Law, which declares that the use of healthcare technologies that have not been assessed or approved shall be prohibited, except in cases provided by law, was passed. The procedure of healthcare technologies assessment and approval was to be established by the Ministry of Health Care. A policy of HTA was approved with the program for HTA in 1999 in the Ministry of Health. Currently, enthusiasts of HTA fully realize that technology assessment is a developing frontier for creative and constructive thinking from all disciplinary view points.

Conclusions: Unfortunately, in this country, there is still a very small demand for HTA reports from the decision-maker's side. Hopefully joining the network of European Union Network for Health Technology Assessment (EUnetHTA) will give a new challenge for further policy development.
\end{abstract}

Keywords: Health technology assessment, History, Lithuania, Health policy

Many European Union (EU) Member States have established formal health technology assessment (HTA) programs or are considering the feasibility of establishing HTA intelligence to inform health policy making (4). Lithuania has developed some experience in that field too. This article presents a case study of the history of development of HTA in Lithuania.

The benefits of HTA became evident in Lithuania after the first visits of Swedish experts beginning in 1993. Policy makers in our country learned about the availability of such research in other countries from such contacts. The Ministry of Health then understood that HTA aims to inform health policy and decision-making processes concerning health technologies.

However, at that time, the definition of HTA was understood in a very technical way: just medical equipment and medications. The major consideration for politicians was to make decisions on purchasing expensive medical equipment, for example, magnetic resonance imaging, computed tomog- raphy scanners, and so on, because of the prices of such equipment, which were a great challenge for the healthcare budget. The methodology for cost-effectiveness assessment of such technology was met with great interest. However, the country was lacking skilled health economists. The universities had not provided students with the specific study programs on this subject.

Thanks to former SBU leader Prof. Egon Jonsson, policy makers in Lithuania understood that HTA has a strong foundation in research on the health effects and broader implications of the use of technology in health care. However, the role of cost-effectiveness, cost efficiency, and cost benefit analysis was not understood in this broader context. It was difficult for the policy makers to differentiate the value of evidence-based medicine and HTA.

In the beginning of 1993, a few conferences on HTA were organized to show how the decision makers of all levels could benefit from HTA reports. Eight people were 


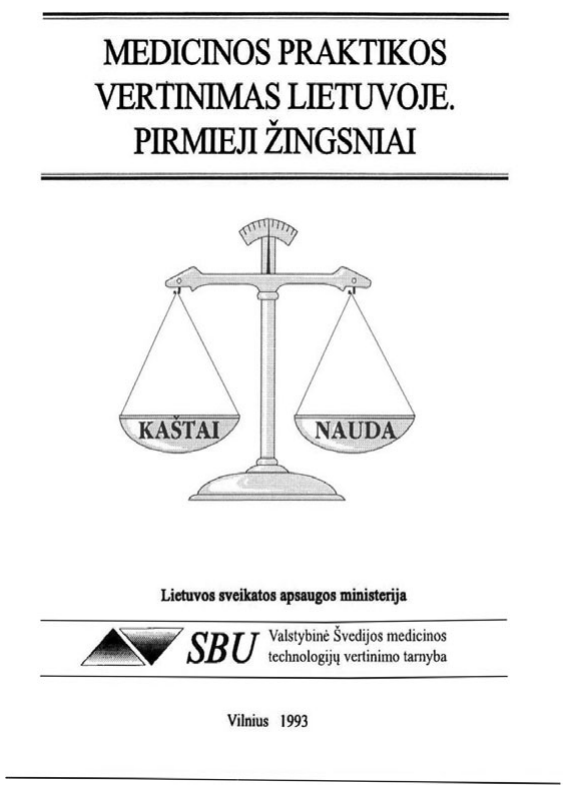

Figure 1. Publication "Health technology assessment in Lithuania: the first steps," SBU, Vilnius, 1993.

trained in Sweden's SBU. The book "First steps of HTA in Lithuania" was issued together with SBU in 1993 (see Figure 1).

The theoretical description of methodologies of HTA was presented along with practical examples of the value of HTA reports (5).

A major development step was participation in International Society of Technology Assessment in Health Care (ISTAHC) conferences and, later, HTAi, conferences as well. Membership in this organization and its training courses as well as information from European networks of HTA made HTA more visible. International experience and the resulting good practices greatly influenced the understanding of the needs of such policy research in Lithuania.

The decision was made to go forward by training the policy makers in the Ministry of Health $(\mathrm{MoH})$ in HTA so that they would understand the need and make decisions on the basis of such information. Unfortunately, due to the old mentality of the leaders and frequent changes of the top civil servants in the $\mathrm{MoH}$, there was no decision to establish a public institution for HTA. Policy makers did not understand the value of systematic reviews for independent assessment of the use and benefit of technologies. Establishment of such an institution remains a challenge in Lithuania.

However, the knowledge developed did not disappear. The emphasis on training continued. New people in HTA were trained in other institutions responsible for health policy: the State healthcare accreditation agency, the State medicines control agency, and the State sickness fund. Those who completed the training have understood that health service delivery is carried out under conditions of growing political and economic complexity and that rapid technologi- cal change puts pressure on healthcare systems (1). To add new preventive, diagnostic, treatment, and rehabilitative interventions to the existing arsenal of technologies, they came to understand that they needed evidence. They began a few evaluations.

Unfortunately, it seems that there was a problem finding properly trained people and also establishing scientific teams. The reports were fragmented and of poor quality. Due to the frequent change of top policy makers and top civil servants in the country, the idea of HTA was always not on the first priority list.

In 1994, a Law of health system was accepted. The important step in HTA development was Article 54, which regulated assessment of healthcare technologies: "The use of health care technologies that have not been assessed or approved shall be prohibited, except in cases provided by law. The procedure of health care technology assessment and approval shall be established by the Ministry of Health Care." Unfortunately, the MoH could not activate such a procedure due to the lack of a proper strategy for HTA development.

In 1999, a program for HTA was created in the $\mathrm{MoH}$, supported by a World Bank project loan. This was an important step forward in the development of HTA activities. Most of activities were related to training and establishment of an EBM library in the country.

In 2001, independent experts established a private independent HTA agency and began to provide state institutions with advice in the form of HTA reports. The expectations were that the state institutions would use these reports for their decision making and then would show interest by asking for more HTA reports. Unfortunately, due to the lack of understanding, lack of financial recourses and lack of a push from private businesses, this activity was not very successful.

The step forward was the decision to require an obligatory pharmacoeconomic evaluation report before registering a new medication in the country. However, there was no requirement to make this report by an independent institution. Therefore, pharmaceutical companies have not been interested in the establishment of an independent HTA institution.

In 2002, the National health board, the institution responsible for health policy coordination in the country, considered the question of HTA development. It was emphasized that, even though there were a lot of efforts on the part of experts and there was foreign technical assistance for HTA development, there was a lack of political will to make priorities and to finance independent HTA reports using the intellectual capacity in the universities, agencies, and state institutions.

Nonetheless, interest in this field has been growing steadily in Lithuania. More sustainability in the development of HTA appeared with the establishment of special master study programs - management of healthcare institutions and health economics in Mykolas Romeris University, where special courses on HTA are provided. This gives a potential for decision makers to not only understand HTA, but also to find expertise in HTA. 
The potential for HTA to contributing to safer and more effective health care is widely acknowledged in Europe and all member States (4). Finally in 2008, MoH has asked State healthcare accreditation service to coordinate the HTA activities in the country. Recently, the Lithuanian State healthcare accreditation agency has joined the European Network for Health Technology Assessment (EUnetHTA) as an associated partner. One may hope that this membership as well as a few ongoing international projects such as the Eastern European and Asian Patients' Organizations for Patients' Rights and Safety (EEAPOPRS) and the European Union Network for Patient Safety project (EUNetPaS) will further the development of HTA in Lithuania.

The Lithuanian case study shows that HTA as a form of health policy multidisciplinary research can be developed only with great cooperation among countries. International cooperation and assistance is very important in the development and improvement of the organization of HTA activities. Currently, enthusiasts of HTA in all countries fully realize that HTA is a developing frontier for creative and constructive thinking from all disciplinary viewpoints (3).

At this point, it is difficult to share results of HTA due to the non $\backslash$ standardized information structure of assessment reports (2) at the international level. Without a universal organization and implementation of assessment reports of health technologies, it is difficult to disseminate information and to share and adapt the results of international assessment reports. It is important to create a sustainable system of cooperation between organizational structures aimed at practical methods, which can improve the evaluation of health technologies.

\section{CONCLUSIONS}

Lithuania is a country that has a good understanding of the need of HTA and produces some HTA reports. However, until the present, HTA activities are very fragmented due to the lack of political will to establish one special coordinating institution and due to the existing gap between researchers and policy makers. The State healthcare accreditation could become such an institution.

The major problems of development of HTA in Lithuania are its definition and institutionalization, the lack of economists and the old mentality of leaders, patients' demands and participation in decision-making process, changes of governments and health ministers, and lack of change in knowledge management.

International cooperation is a major factor influencing development of HTAEuropean countries.

\section{CONTACT INFORMATION}

Danguole Jankauskiene, MD, PhD (djank@mruni.lt), Associate Professor, Vicedean of Strategic Management an Policy Department, Mykolas Romeris University, 20 Ateities Street, Vilnius LT08303, Lithuania

\section{REFERENCES}

1. Burns A, Charlwood P, Darling H, et al. Better information, better outcomes? The use of health technology assessment and clinical effectiveness data in health care purchasing decisions in the United Kingdom and the United States. New York, Milbank Memorial Fund 2000. http://www.milbank.org/ reports/000726purchasing.html (accessed 28 November 2008).

2. Caplan N. A minimal set of conditions necessary for the utilization of social science knowledge in policy formulation at the national level. In: Weiss $\mathrm{CH}$, ed. Using social research in public policy making. Toronto; Lexington Books; 1977:183-198.

3. Choi BC, Pang T, Lin V, et al. Can scientists and policy makers work together? J Epidemiol Community Health. 2005;59:632637.

4. Garrido VM, Kristensen FB, Nielsen CP, Busse R. Health technology assessment and health policy-making in Europe. Current status, challenges and potential. World Health Organization, European Observatory on Health Systems and Policies, Observatory studies, No, 14, 2008, P.90-92.

5. Jonsson E, Usonis V, Jankauskiene D, et al. First steps of HTA in Lithuania. Vilnius: Ministry of Health; 1993. 